\title{
18
}

\section{The Kuk Artefacts, an Introduction}

\author{
Jack Golson
}

The next three chapters deal with stone and wooden objects recovered in the course of investigations of the cultivation and living areas that have been the subject of previous chapters or collected from adjacent properties. The stone material is divided between Chapter 20, mainly flaked and ground tools with use wear and organic residues giving evidence of subsistence, and Chapter 21, mainly ground and polished axes and fragments giving evidence of trade. The wooden finds are dealt with first, in Chapter 19. Before we embark on these chapters, however, we need to consider the circumstances in which the finds were made, processed and stored, because these are relevant to a consideration of their contribution to our understanding of the site.

\section{The circumstances of discovery and retrieval}

There are a number of points to be made about the discovery and retrieval of artefacts at Kuk.

There were fewer finds made by archaeological excavation than during the drain digging carried out to give us access to the swamp deposits for our investigation. This was particularly the case with the more than $12 \mathrm{~km}$ of major channels that were needed to drain the eastern half of the Research Station, where we were to work, and to provide the infrastructure of roads for its future development. The job was started by Station workmen in mid-1972 and went on for about three months. The $15 \mathrm{~km}$ of mainly minor drains for which we were responsible over the years 1972-77 were dug for our own purposes, by our own workmen, in conformity with the Station plan. These workmen were aware of the need to watch out for finds of stone and wood, even though drain digging often did not allow certainty about the location of the finds that were made.

The areas of the site used for cultivation or pasture in the prehistoric past were much poorer in associated finds than the housing areas, apart perhaps from the wooden stakes of fences, while most of the houses belonged to Phase 6. Two of the small number of identified Phase 5 houses were unknown until excavations revealed them beneath Phase 6 houses, so it is difficult to make a realistic assessment of the extent of Phase 5 housing and associated items. Not only were houses unknown in the swamp before Phase 5, so too were preserved wooden artefacts, as discussed in Chapter 19, section 'The Steensberg catalogue' (cf. Powell 1982b: 28, 30).

The cultivations of Phases 4-6 were characterised by grid patterns of long straight ditches crossing at right angles. They were mapped from the appearance of the constituent ditches in the walls of the Station drains that were dug at intervals of $22.5 \mathrm{~m}$ across, as discussed and depicted in Chapters 14-16. It was in general unnecessary to dig out the ditches to study the organisation of the cultivation system, but this meant forgoing recovery of any stone and wooden objects that 
might be there. Because there were no Phase 4 houses in the swamp, Phase 4 is impoverished in associated finds in comparison with Phase 6 , while Phase 5 should be less so. In addition, these three phases belong within the 'garden soils' of the Kuk stratigraphic column (see Figs 6.10 and 6.11). There is a large category of stone finds that cannot be dated more precisely than Phases 4-6 because of uncertainty as to where they had belonged in those soils before being unearthed by drain digging.

Like Phase 4, Phase 3 is poor in associated material because it lacks houses in the swamp and because it has a field system that was studied with a minimum of excavation of the constituent ditches. The organisation of the Phase 3 system could not be reconstructed from the appearance of its ditches in drain walls, because this was not systematic as in Phases 4-6, so it was necessary to follow the ditches using their clear imprint at the surface of the grey clay that is a marked feature of the Kuk stratigraphy (cf. Fig. 13.10).

To understand Phases 1 and 2 required total excavation and recovery in area excavations in the southeast corner of the Station, which therefore included attention to any evidence from later phases. However, the areas selected, in blocks A11 and A12, had had minimal interference from Phase 4 and 6 activity.

\section{The circumstances of curation, and its failures}

\section{Wood}

It was, of course, the waterlogged wood that was of immediate concern from a curatorial point of view. Conservation facilities for such material had been developed at ANU by Wal Ambrose over the five years since the Manton excavations, in which he had taken part. These had shown the potential of the upper Wahgi wetlands for archaeological research into agricultural history and encouraged us to commit our department to the task. Ambrose aimed to provide a method of conservation for waterlogged timber that promised more efficient operation and superior results to the techniques of the time. He developed the freeze-drying procedure that has become standard practice (Ambrose 1975; cf. Golson 1996: 158-159).

The problem was one of preventing objects from drying out before and during their shipment back to the Canberra laboratory. This was particularly the case during the long 1972 season when the major drainage lines were being dug and large amounts of wood unearthed. Ambrose was at Kuk over this period with various responsibilities, including giving appropriate treatment in the field to waterlogged wooden objects of different kinds and at different stages of deterioration. We were occasionally lucky enough then, and in later years, to arrange for material to be flown from Mount Hagen to the Royal Australian Airforce base outside Canberra on aircraft returning empty from official missions to Papua New Guinea. After each major season of wood recovery-1972, 1974 and 1975-there were always pieces too degraded to be sent off from Kuk or not in a good enough state, or of sufficient importance, to justify the time and effort of conservation, for which there was always a queue.

Storage for the conserved specimens was never satisfactory at ANU during the 1970s and early 1980s. There were changes of location and supervision of the items and their records during which some losses of each occurred. This was partly because the wooden objects did not attract the same level of attention as the stone items. Laurie Lucking, a University of Minnesota student who came to work at Kuk during summer breaks in 1973 and 1974, developed a strong interest in the wooden finds, both artefactual and not, and their botanical identification. After the 1975 PNG season, she was employed by the ANU Department of Prehistory to work on the wood 
finds stored there, after which she took part in the 1976 season at Kuk. Her direct involvement with the project ended when her application for an ANU scholarship to continue her Kuk wood and seed research was unsuccessful. Her records form a part of the Kuk archive that has not been much used since she left in 1976. In 1983, Axel Steensberg, who had worked at Kuk in 1975, came to the Department of Prehistory as a Visiting Fellow and compiled a catalogue of the wooden artefacts from Kuk and elsewhere (see Chapter 19).

\section{Stone}

Each Kuk field season contributed to a growing collection of stone artefacts in Canberra, which was housed separately from the wooden artefact collection. Material from these collections was withdrawn in batches for cataloguing by Golson with two ANU undergraduate students of archaeology, Kieran Hotchin and Peter May. By the beginning of the 1980s, a catalogue of some 750 cards had been compiled, identifying each object or collection of closely associated objects by a code comprising the site, the year of collection, $S$ for stone (W for wood in the parallel, pre-Steensberg, wood catalogue) and a unique number for the object itself, e.g. K/72/S12, K/75/ S18A, B. Information entered on each card included a brief description of the object or objects in question, details of the findspot and sometimes, from this, the relative age, as well as observations about the context of the discovery as it was then understood. The stone finds were then ready to make their contribution to the study of Kuk and its place in the wider world of the PNG highlands.

In 1980, John Burton came to ANU from the UK as a PhD scholar to study axe manufacture and the axe trade in the Wahgi region, for which he made use of archaeological finds of axes and parts of axes found at Kuk. The results of this and associated work on stone sourcing are discussed in Chapter 21.

In 1987, we hired Tom Loy of the Royal British Columbia Museum, a pioneer in the study of organic residues on stone tools, to set up a residue laboratory at ANU. Loy was joined in 1988 by Barry Fankhauser, who had a doctorate on the chemistry of residues from Maori earth ovens and the thermoluminescence dating of their ovenstones. In 1991, Loy inspected stone material from Kuk and made a selection of items with potential for usewear and/or organic residue analysis. Loy recorded his examination of 88 items, out of which he selected 58, which were stored in the residue laboratory for future attention. That attention came in the later 1990s when Tim Denham commenced a PhD at ANU for a project of field and laboratory research into the early phases of the Kuk agricultural sequence. His aim was to test the claims that had been made on the basis of the Kuk work of the 1970s for early and independent origins of agriculture in New Guinea. Denham thus became heir to 19 items from Phases 1-3 that were part of the Loy selection of 58 Kuk items with organic residues and usewear, 13 of the 19 being from the 1975-77 investigations in the southeastern blocks of the Station. Denham enlisted the services of Richard Fullagar, then of the University of Sydney, for their study.

By the time of Denham's work, most of the department's archaeological collections, comprising all the Kuk stone but only some of the wood, had been moved off campus into a store at Weston on the urban fringe of Canberra. The materials that Denham had used for his research had not been reunited with the main Kuk stone collection when the Weston store went up in flames during a daytime firestorm that hit Canberra's western suburbs on 18 January, 2003 (Swete Kelly and Phear 2004). The concrete slab ceiling of the archaeology store and its brick walls collapsed and compacted the materials underneath. Before the fire, these had been densely packed by region and site. With the destruction of the boxes and bags in which most of the objects had been stored, remains were mixed up and identifying labels largely destroyed. 


\section{The aftermath of the Weston fire}

Salvage efforts over subsequent months consisted of excavation to recover the archaeological materials horizontally in terms of a grid of excavation squares and vertically in terms of the stratigraphy of the deposit. This first step in the salvage process was the subject of Swete Kelly and Phear's 2004 report.

The second step was to use the locational information provided by the salvage excavations to track down the collections to which items might have originally belonged by reference to catalogues indicating where particular collections had been situated in the store. Other evidence such as surviving labels or catalogue numbers, distinctive features of particular collections and the like then came into play. The university made space and basic facilities available for this painstaking work at Spring Valley Farm, a rural property some 6-7 km from the burnt-out store. It resulted in a large report discussing the results achieved and the basis they provided for further work (Swete Kelly and Hunt 2006). However, as Richard Fullagar points out in Chapter 20, there was limited success in making use of the material that the salvage operations had identified as likely to belong to Kuk. Adam Black, a recent ANU student who had had good results in digitally enhancing the legibility of photographs of Australian rock art, was recruited to work with Fullagar and Golson to provide digital images of potentially readable catalogue numbers on stone artefacts or information on labels associated with them. However, the results did not warrant the time and labour involved.

As Denham and Ballard have said (2003: 131), the Weston episode highlights the danger of delay in the study and publication of excavated materials. We were essentially unable to use some 90 per cent of the stone recovered at Kuk between 1969 and 1977 and very fortunate that the 10 per cent available for study was as productive as it proved to be.

The wooden finds have their own story to tell. We are concerned here with the material brought down from Mount Hagen to Australia and catalogued at ANU in 1983 with numbers prefixed by 'A'. This was to distinguish them from other catalogued items that remained in PNG, as described in Chapter 19. In the introduction to his 1983 catalogue, Steensberg says that he drew all the A-catalogued items at full scale, and that they numbered 504, but he actually dealt with 511 (see Table 18.1). A small number of these wood finds was transferred with the Kuk stone collection to the Weston store when it was set up. Those left on campus were there until 2003, when they were sent to Spring Valley Farm to join the material recently salvaged from the Weston store. When Golson and Adam Black later inventoried the wooden material at Spring Valley, they found that 61 pieces were missing from the 511 items catalogued in 1983. Some of them were, no doubt, victims of the fire.

There is, however, another part to the story of the wooden items catalogued by Steensberg. In the catalogue, these are arranged in groups according to the purposes for which they were useddigging sticks, spades and so on. Within these groups each entry is identified by the designation given to it in the field, usually in the form described for the stone finds, i.e. site, year, material and a unique number, thus K/75/W12. These entries begin with the finds from Kuk, followed (in the main) by those from elsewhere in the upper Wahgi and concluding with others lacking any field identification. One hundred of the 511 wood finds that Steensberg had catalogued (Table 18.1) reflect the loss of labels or field documentation in the conditions described above. The annotations that subsequently appeared in the Steensberg catalogue, as work on the wood collection proceeded, testify to continuing difficulties with the harmonisation of the field records and, to a minor extent, disagreements with Steensberg's ascription of function to particular items.

Because of uncertainty over the findspot of many items, the treatment of the wooden artefacts in Chapter 19 is a straightforward account of the objects recovered, with little attempt at analysis in the context of the site, except, to some extent, for the fence stakes. 
Table 18.1 Wooden tools catalogued, with an A prefix, by Steensberg in 1983 by category and provenance, followed (in brackets) by the numbers missing from the inventory undertaken in 2003.

\begin{tabular}{|l|r|r|r|r|}
\hline Category & \multicolumn{1}{|c|}{ Kuk } & Upper Wahgi & \multicolumn{1}{c|}{ Unknown } & \multicolumn{1}{c|}{ Totals } \\
\hline (I) levers and planting sticks & $39(16)$ & $5(3)$ & $20(4)$ & $64(23)$ \\
\hline (II) women's sticks for tuber harvest & $49(4)$ & $25(0)$ & $22(2)$ & $96(6)$ \\
\hline (III) long paddle spades & & & & \\
\hline a) spatulate & $2(0)$ & $10(4)$ & $7(1)$ & $19(5)$ \\
\hline b) shouldered & $1(1)$ & $6(0)$ & $11(2)$ & $18(3)$ \\
\hline (IV) paddle spades with counterweights & $0(0)$ & $1(1)$ & $3(0)$ & $4(1)$ \\
\hline (V) double paddle spades & $2(0)$ & $1(1)$ & $0(0)$ & $3(1)$ \\
\hline (VI) short paddle spades & $2(0)$ & $2(1)$ & $3(0)$ & $7(1)$ \\
\hline (VII) axe hafts & $2(2)$ & $6(6)$ & $1(1)$ & $9(9)$ \\
\hline (VIII) headrests & $5(0)$ & $0(0)$ & $3(0)$ & $8(0)$ \\
\hline (IX) clubs & $1(0)$ & $0(0)$ & $4(0)$ & $5(0)$ \\
\hline (X) weapons & $2(1)$ & $1(1)$ & $0(0)$ & $3(2)$ \\
\hline (XI) house timbers and fence stakes & $195(6)$ & $29(1)$ & $17(1)$ & $241(8)$ \\
\hline (XII) unidentified items & $24(2)$ & $1(0)$ & $9(0)$ & $34(2)$ \\
\hline Total & $324(32)$ & $87(18)$ & $100(11)$ & $511(61)$ \\
\hline
\end{tabular}

\section{Acknowledgements}

ANU undergraduate archaeology students Kieran Hotchin and Peter May were hired to help with the original cataloguing of the Kuk stone, which they did with intelligence and good humour. I thank Adam Black for his assistance with the inventory of wooden artefacts in the wake of the 2003 bushfire and Alexandra Chiragakis for its tabulation. 
This text is taken from Ten Thousand Years of Cultivation at Kuk Swamp in the Highlands of Papua New Guinea, edited by Jack Golson, Tim Denham, Philip Hughes, Pamela Swadling and John Muke, published 2017 by ANU Press, The Australian National University, Canberra, Australia. 